\title{
Application of linkage analysis to genetic counselling in families with hereditary retinoblastoma
}

\author{
VALERIE GREGER*, STEFAN KERST*, ELMAR MESSMER†, \\ WOLFGANG HÖPPING $†$, EBERHARD PASSARGE*, \\ AND BERNHARD HORSTHEMKE* \\ From ${ }^{*}$ Institut für Humangenetik and †Zentrum für Augenheilkunde, Universitätsklinikum Essen, Federal \\ Republic of Germany.
}

SUMMARY Six families with retinoblastoma in more than one member were investigated with DNA markers linked to the retinoblastoma locus because direct analysis had not disclosed the gene defect. In all of the families we could identify the affected chromosome and predict the genetic risk with a high level of confidence (90 to $99 \%$ ). In one patient the test helped to detect tumour development earlier than usually possible. Several subjects were found not to carry a mutation, thus obviating frequent ophthalmological examinations under anaesthesia as would be necessary otherwise. These results show that linkage analysis can be successfully applied to genetic counselling in families with hereditary retinoblastoma.

Retinoblastoma $(\mathrm{Rb})$ belongs to a group of childhood tumours predisposition to which can be inherited as an autosomal dominant trait. ${ }^{1}$ The gene locus has been assigned to the long arm of human chromosome 13 , region 1 , band $4 .^{2}$ Two genetic events are assumed to be required to initiate tumour formation. ${ }^{3}$

In hereditary retinoblastoma ( $40 \%$ of cases), the patients carry a germinal mutation at one of the two homologous $\mathrm{Rb}$ loci in all their cells. Retinoblastoma develops from a retinoblast that has lost the wild type allele on the homologous chromosome, either by mitotic non-disjunction, mitotic crossing over, gene conversion, deletion, or point mutation during the development of the retina. ${ }^{4}$ Mitotic non-disjunction and crossing over occur in approximately $50 \%$ of tumours and lead to hemior homozygosity for all or part of chromosome $13 .^{5}$

Patients with hereditary retinoblastoma usually have bilateral or multifocal unilateral retinoblastoma. However, a small number of these patients develop only one tumour or do not have tumour development at all.

In about one-third of patients with hereditary retinoblastoma, the first mutation has been transmitted from an affected parent. In this situation, sibs and offspring have a genetic recurrence risk of $50 \%$. In the other patients with hereditary retinoblastoma, a new mutation has occurred spontaneously in a

Received for publication 29 September 1987 Accepted for publication 5 November 1987. parental germ cell. In these families offspring, but not sibs, of the patient are at increased risk.

In about $60 \%$ of all retinoblastoma patients tumour formation results from two independent somatic mutations in the same retinoblast. This is non-hereditary retinoblastoma, which is always unifocal and unilateral, and neither sibs nor offspring are at an increased risk.

Unfortunately these different genetic forms of retinoblastoma and the different genetic risks they confer cannot be readily distinguished in clinical practice. This leads to uncertainties about the genetic risk, which may be over- or underestimated.

A predictive test that would distinguish persons destined to develop retinoblastoma from those who will not would obviously be of great help for genetic counselling and early ophthalmological diagnosis. Advances in molecular genetics during the last few years have led to the development of molecular probes for the $R b$ gene $^{6-8}$ and other loci on chromosome $13 .^{9-12}$ Some of these probes can detect directly a certain proportion of deletions at the $\mathrm{Rb}$ locus, ${ }^{6-813} 14$ but most mutations escape direct analysis at present.

In families not amenable to direct analysis of the gene defect, an indirect diagnosis can be achieved if the affected chromosome can be identified through genetic linkage analysis. Only one attempt using this approach to predict the development of retinoblastoma has been reported previously. ${ }^{15}$ In the meantime, much closer markers have become 
available. We have studied nine families with hereditary retinoblastoma and in three a microdeletion was directly detectable. ${ }^{16}$ Here we describe indirect diagnosis based on linkage analysis in the six families not amenable to direct gene analysis.

\section{Methods}

\section{PATIENTS}

Families with hereditary retinoblastoma were ascertained either through the Retinoblastoma Clinic of the Department of Ophthalmology or the Genetics Clinic of the Department of Human Genetics, University of Essen, between March 1986 and May 1987. The diagnosis of retinoblastoma had been established by current ophthalmological and histological criteria.

\section{DNA ANALYSIS}

Total genomic DNA from whole blood and from retinoblastomas obtained after enucleation was digested with appropriate restriction enzymes. The DNA fragments were separated by gel electrophoresis, transferred to nylon membranes, and hybridised with the appropriate probes as described previously. ${ }^{14}$ The strategy for the use of the DNA probes (table) involved two stages. In the first stage, only $13 q 14$ probes were used. Families found not to be informative for any of these markers were then investigated at more distant loci.

\section{RISK CALCULATIONS}

Risk estimates were calculated by hand and checked using the LINKAGE programme on a Compaq 286 personal computer. ${ }^{17}$ For computer analysis we assumed autosomal dominant inheritance, a pene- trance of $0 \cdot 9$, a gene frequency of $0 \cdot 00005$, and a sex difference in recombination of $3 \cdot 8 .{ }^{18}$

\section{Results}

Six families with retinoblastoma in more than one member were studied by genetic linkage analysis. As shown in the figure, all six families were informative for at least one 13q14 marker or two. more distant but flanking markers.

FAMILY 1 (MI-0192)

Subject II. 2 is a 25 year old male without any signsọ of retinoblastoma. However, owing to reduced ज penetrance he had to be assumed to have a 5\% risk + of carrying a mutation. DNA analysis revealed that ${ }_{-}^{N}$ he has inherited from his affected mother the $v$ chromosome 13 not carrying the mutation, unless 5 two crossovers have occurred between the two $\rightarrow$ marker loci 7D2 and 9D11. Since the chance of ao double crossover is $0.05 \times 0.4=0.02$, and only $10 \%$ of carriers do not develop the disease, he has a risk $\vec{\bullet}$ of $0.02 \times 0 \cdot 1=0 \cdot 002$. Thus, his actual risk of being aळ carrier and transmitting the mutation is much lower $\square$ (approximately $0 \cdot 2 \%$ ) than the original estimate based on formal genetics. This information is important for his family planning.

FAMILIES 2,3, AND 4 (FE-0006, MO-0155, AND OL-0162)

These three families, who have small children with retinoblastoma, have asked about the risk for future children and the availability of a predictive genetic test. Family FE-0006 is informative for the intragenic $\mathrm{H} 3-8$ HindIII restriction fragment length polymorphism. ${ }^{14}$ The mutation segregates with

TABLE Details of the probes used.

\begin{tabular}{|c|c|c|c|c|c|c|c|}
\hline \multirow[t]{2}{*}{ Probe } & \multirow{2}{*}{$\begin{array}{l}\text { Chromosomal } \\
\text { localisation }\end{array}$} & \multicolumn{3}{|c|}{ Recombination fraction used for counselling } & \multirow[t]{2}{*}{ Enzyme } & \multirow[t]{2}{*}{$P I C$} & \multirow[t]{2}{*}{$\operatorname{Ref} N o$} \\
\hline & & Males & Females & Combined & & & \\
\hline \multirow[t]{2}{*}{ Hul0 } & \multirow[t]{2}{*}{$13 q 12-14$} & \multirow[t]{2}{*}{$0 \cdot 1$} & \multirow[t]{2}{*}{$0 \cdot 3$} & & $X m n \mathrm{I}$ & $0 \cdot 29$ & 18 \\
\hline & & & & & EcoRI & 0.25 & 18 \\
\hline \multirow[t]{2}{*}{$7 F 12$} & \multirow[t]{2}{*}{$13 q 12-14$} & \multirow[t]{5}{*}{$0 \cdot 07$} & \multirow[t]{5}{*}{$0 \cdot 21$} & & TaqI & 0.36 & 18 \\
\hline & & & & & $M s p I$ & 0.36 & 18 \\
\hline G14E1.9 & $13 q 14$ & & & $0 \cdot 1$ & DraI & $0 \cdot 34$ & 11 \\
\hline \multirow[t]{2}{*}{ 7D2 } & \multirow[t]{2}{*}{$13 q 14$} & & & \multirow[t]{2}{*}{0.05} & TaqI & $0 \cdot 14$ & 18 \\
\hline & & & & & DraI & $0 \cdot 35$ & 19 \\
\hline \multirow[t]{2}{*}{ ESD } & \multirow[t]{2}{*}{$13 q 14$} & & & \multirow[t]{2}{*}{$0 \cdot 01$} & ApaI & 0.27 & 12 \\
\hline & & & & & BanII & 0.35 & $*$ \\
\hline H3-8 & $13 q 14$ & & & 0.01 & HindIII & 0.05 & 14 \\
\hline Hu26 & $13 q 22$ & 0.18 & 0.4 & & $B g l l l$ & $0 \cdot 18$ & 18 \\
\hline \multirow[t]{2}{*}{$9 \mathrm{D} 11$} & \multirow[t]{2}{*}{$13 \mathrm{q} 22$} & \multirow[t]{2}{*}{$0 \cdot 18$} & \multirow[t]{2}{*}{$0 \cdot 4$} & & TaqI & 0.24 & 18 \\
\hline & & & & & $M s p I$ & 0.37 & 18 \\
\hline $1 \mathrm{E} 8$ & $13 q 31-34$ & $0 \cdot 2$ & 0.47 & & MspI & 0.37 & 18 \\
\hline \multirow[t]{2}{*}{ HuB8 } & \multirow[t]{2}{*}{$13 q 31-34$} & \multirow[t]{2}{*}{$0 \cdot 2$} & \multirow[t]{2}{*}{0.47} & & EcoRI & 0.24 & 18 \\
\hline & & & & & HindIII & 0.28 & 18 \\
\hline
\end{tabular}




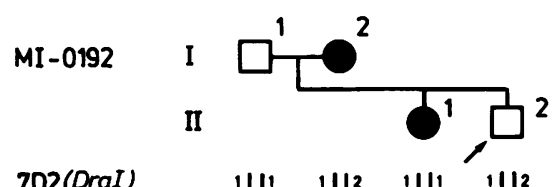

RB

9D11(MspI)

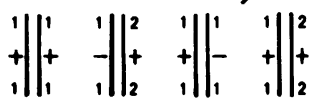

FE - 0006

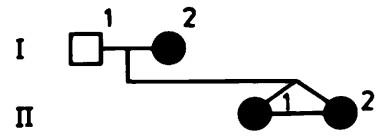

H3-8 (HindIII)

RB

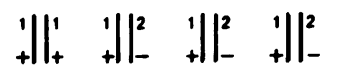

OL-0162

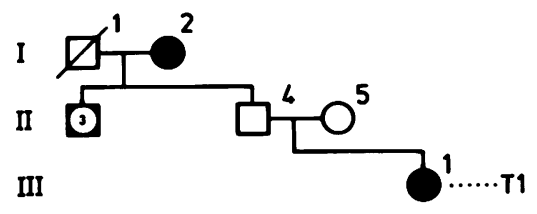

$\operatorname{ESD}(A p a I)$

RB

H3-8 (HindIII)

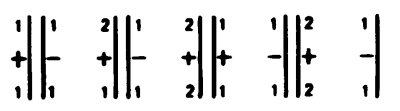

WE-0078
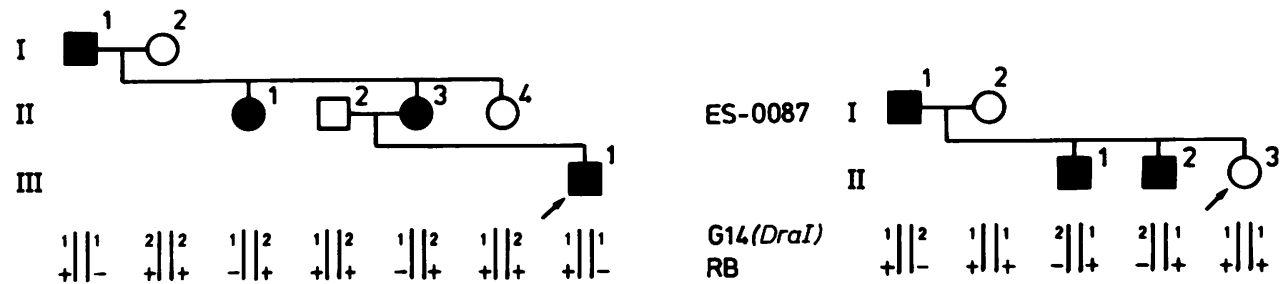

$\operatorname{ESD}($ ApaI) RB

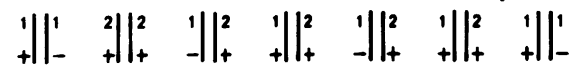

RB

FIGURE DNA analysis in six families with hereditary retinoblastoma. The results for the closest informative loci only are given. In subject II.4, family WE-0078, the association of ESD allele I with Rb+ was inferred from other markers which are not shown in the figure. Solid symbols indicate affected subjects. $T 1, T 2$, tumours; $R b+$, wild type allele; Rb-, mutant allele. The arrows indicate the subjects in whom DNA diagnosis was performed.

allele 2 , and the absence or presence of this allele in a subsequent offspring would predict the absence or presence of the mutation. Since recombination between the mutation and the polymorphic site in the $\mathbf{R b}$ gene is very unlikely, the confidence interval of a diagnosis would be about $99 \%$.

In families $\mathrm{MO}-0155$ and $\mathrm{OL}-0162$, tumour material was also available for DNA analysis. Although knowledge of the tumour genotype was not essential for the diagnosis in these two cases, the loss of constitutional heterozygosity in two tumours allowed the linkage phase to be established easily. Taking the chance of a double crossover between probes 7F12 and HuB8 into account, the confidence interval of a DNA diagnosis in family MO- 0155 would be $98 \%$. Since family OL-0162 is informative for the closely linked markers ESD and H3-8, here the confidence interval of a DNA test would be $99 \%$.

Interestingly, one of the two tumours present in the left eye of subject II.1, family MO-0155, had maintained constitutional heterozygosity (T1), whereas heterozygosity had been lost in the other tumour (T2). This proves that different somatic mutations have led to the formation of these two tumours.

FAMILIES 5 AND 6 (WE-0078 AND ES-0083) These two families had newborn babies and requested a predictive DNA test on umbilical cord blood. Family WE-0078 was informative for the closely linked marker ESD. Child III.1 was found to have inherited the affected chromosome at a confidence level of $99 \%$. He was first examined four 
weeks after birth and found to have two small tumours in his left eye. The presence of another tumour in his right eye was suspected at that time. Three weeks later a small tumour had developed there. The tumours were successfully treated by light and cryocoagulation, but the patient developed several new tumours, and external beam radiation was necessary to stop tumour growth.

Family ES -0083 was informative for the marker G14E1.9 and the mutation was unlikely to be present in the subject II.3 at a confidence level of about $90 \%$. Up to the age of one year the child has not developed any signs of a retinoblastoma.

\section{Discussion}

Using cloned DNA probes linked to the retinoblastoma gene locus on chromosome 13, we have been able to offer predictive genetic tests to six families with hereditary predisposition to this disease. In most cases the confidence level was close to that of direct gene diagnosis, which we have recently performed in three other families. ${ }^{16}$ Although probes and techniques are now being developed for detecting point mutations within a gene ${ }^{20}{ }^{21}$ most mutations at the Rb locus cannot at present be detected directly. Furthermore, owing to a high mutation rate ${ }^{1}$ and negative selection, the mutations are expected to be heterogeneous. In contrast to many haemoglobin mutants, heterogeneity will make it difficult to apply the same approach in many families. Thus, linkage analysis will remain useful in many families despite its drawbacks, such as the need for a full family analysis and the risk of recombination between the marker and the retinoblastoma locus. The latter problem, however, will be overcome as more intragenic RFLPs are being identified.

In the families studied here, a minimum of two subjects were affected by the disease. Indirect DNA diagnosis can also be performed in families with only one affected member provided the patient has bilateral or multifocal unilateral retinoblastoma (that is, carries a germinal mutation) and has at least one child that has passed the age of onset (usually two to three years of age). However, owing to reduced penetrance of mutations at the $\mathrm{Rb}$ locus, there is a $10 \%$ risk that such a child does carry the mutation, thus rendering indirect DNA diagnosis less accurate in these cases. If tumour DNA can be obtained (from fresh material, cultured cells, or histological specimens), and it is found to be hemior homozygous for part or all of chromosome 13, the affected chromosome can be identified directly. This would improve the confidence in diagnosis in these cases and make it possible to perform the diagnosis in the first child also. Therefore, every effort should be made to save tumour material.

DNA diagnosis in retinoblastoma, either by direct $\frac{\overrightarrow{0}}{0}$ or by indirect analysis of the gene defect, can be 등 helpful for retinoblastoma families in several ways. $\frac{\bar{\sigma}}{\overline{0}}$ Some families with several severely affected patients may wish to consider prenatal diagnosis. Newborn infants and young children carrying a predisposing $ळ$ germinal mutation could be examined every two to $\overrightarrow{0}$ four weeks immediately after birth. Children found $\vec{\overrightarrow{ }}$ not to be at risk could be spared unnecessary $\vec{\sigma}^{\circ}$ ophthalmological examinations, which in very young children require general anaesthesia. Finally, clinically unaffected sibs and offspring planning to start a family of their own may want to know that $\rightarrow$ they really do not carry the mutation at the $R b \underset{\sim}{\sim}$ locus. Our results show that these questions can now $\vec{v}$ be answered in many families with a relatively high 음 level of confidence.

This work was supported in part by research $\frac{D}{0}$ grants from the Deutsche Forschungsgemeinschaft. We would like to thank Drs C H C M Buys, $\vec{\varphi}$ Groningen, W K Cavenee, Montreal, T P Dryja, $\infty$ Boston, S A Latt, Boston, and J Squire, Toronto, for providing the DNA probes; Drs C H C M Buys and $J$ Squire for the communication of unpublished results; Dr B Fischer, Kiel, for referring family MI-0192, and H J Barnert for expert technical assistance.

\section{References}

1 Vogel F. Genetics of retinoblastoma. Hum Genet 1979;52:1-54.

2 Sparkes RS, Sparkes MC, Wilson MG, et al. Regional assignment of esterase $D$ and retinoblastoma to chromosome band 13q14. Science 1980;208:1042-4.

3 Knudson AG Jr. Mutation and cancer: statistical study of retinoblastoma. Proc Natl Acad Sci USA 1971;68:820-3.

4 Cavenee WK, Dryja TP, Phillips RA, et al. Expression of recessive alleles by chromosomal mechanisms in retinoblastoma. Nature 1983;305:779-84.

5 Dryja TP, Cavenee WK, White RL, et al. Homozygosity of 0 chromosome 13 in retinoblastoma. $N$ Engl J Med 1984;310: 550-3.

6 Friend SH, Bernards R, Rogelj S, et al. A human DNA segment with properties of the gene that predisposes to retinoblastoma and osteosarcoma. Nature 1986;323:643-6.

${ }^{7}$ Lee WH, Bookstein R, Hong F, Young LJ, Shew JY, Lee EYHP. Human retinoblastoma susceptibility gene: cloning, identification, and sequence. Science 1987;235:1394-9.

8 Fung YKT, Murphree AL, T'Ang A, Qian J, Hinrichs SH C Benedict WF. Structural evidence for the authenticity of the human retinoblastoma gene. Science 1987;236:1657-61.

9 Cavenee WK, Leach R, Mohandas T, Pearson P, White R. Isolation and regional localization of DNA segments revealing polymorphic loci from human chromosome 13. Am J Hum Genet 1984;36:10-24.

10 Lalande M, Dryja TP, Schreck RR, Shipley J, Flint A, Latt SA. Isolation of human chromosome 13 DNA sequences cloned from flow-sorted libraries. Cancer Genet Cytogenet 1984;13: 283-95.

11 Scheffer $\mathrm{H}$, van der Lelie D, Aanstoot GH, et al. A straight- $\frac{\sigma}{<}$ forward approach to isolate DNA sequences with potential $?$ 
linkage to the retinoblastoma locus. Hum Genet 1986;74: 249-55.

12 Squire J, Dryja TP, Goddard A, et al. Cloning of the esterase D gene: a polymorphic gene probe closely linked to the retinoblastoma locus on chromosome 13. Proc Natl Acad Sci USA 1986;83:6337-41.

13 Dryja TP, Rapaport JM, Joyce JM, Petersen RA. Molecular detection of deletions involving band q14 of chromosome 13 in retinoblastomas. Proc Natl Acad Sci USA 1986;83:7391-4.

${ }^{14}$ Horsthemke B, Greger V, Barnert HJ, Höpping W, Passarge E. Detection of submicroscopic deletions and a DNA polymorphism at the retinoblastoma locus. Hum Genet 1987;76: 257-61.

15 Cavenee WK, Murphree AL, Shull MM, et al. Prediction of familial predisposition to retinoblastoma. $N$ Engl $J$ Med 1986;314:1201-7.

16 Horsthemke B, Barnert HJ, Greger V, Passarge E, Höpping W. Early diagnosis in hereditary retinoblastoma by detection of molecular deletions at gene locus. Lancet 1987;i:511-2.

17 Lathrop JM, Lalouel JM, Julier C, Ott J. Strategies for multilocus linkage analysis in humans. Proc Natl Acad Sci USA 1984;81:3443-6.

${ }^{18}$ Leppert M, Cavenee WK, Callahan P, et al. A primary genetic map of chromosome 13q. Am J Hum Genet 1986;39:425-37.

19 Bowcock AM, Farrer LA, Hebert JM, et al. A new human RFLP identified by 7D2 places D13S10 proximal to esterase D. Cytogenet Cell Genet 1987;44:236-7.

20) Conner BJ, Reyes AA, Morin C, Itakura K, Teplitz RL, Wallace B. Detection of sickle cell $\beta$-globin allele by hybridisation with synthetic oligonucleotides. Proc Natl Acad Sci USA 1983;80:278-82.

${ }^{21}$ Myers RM, Larin Z, Maniatis T. Detection of single base substitutions by ribonuclease cleavage at mismatches in RNA: DNA duplexes. Science 1985;230:1242-6.

Correspondence and requests for reprints to Dr B Horsthemke, Institut für Humangenetik, Universitätsklinikum, Hufelandstrasse 55, D-4300 Essen 1, Federal Republic of Germany. 